\title{
Improvement of Efficacy of Antitumor Agents by Conagenin
}

\author{
Masaji KaWatsu, TaKashi Yamashita, MasaAki IshizuKa* \\ and TOMTO TAKEUCHI \\ Institute for Chemotherapy, M.C.R.F., \\ 18-24 Motono, Miyamoto, Numazu, \\ Shizuoka 410-03, Japan
}

(Received for publication September 8, 1994)

\begin{abstract}
The antitumor efficacy of antitumor agents at sublethal doses was investigated in combination with conagenin (CNG) against murine leukemias. Mice were inoculated with $1 \times 10^{3} \mathrm{~L} 1210$ cells iv and given $300 \mathrm{mg} / \mathrm{kg}$ of cyclophosphamide (CY) ip on days 1 and 2 or on days 1,5 and 9 after the tumor inoculation, and $5 \mathrm{mg} / \mathrm{kg}$ of CNG daily for 10 days. The administration of CNG was effective in increasing the number of cured mice and in prolonging the survival period of mice significantly, on both schedules of CY treatment. Moreover, the antitumor effect of CY against EL-4 was enhanced by CNG in increasing the number of cured mice, in CY treatment on days 1 and 2, and on days 1 , 5 and 9.

The effect of CNG was examined with mitomycin C (MMC) and adriamycin (ADM) at sublethal doses against leukemias. The antitumor effects of MMC at $10 \mathrm{mg} / \mathrm{kg}$ against L1210, and ADM at $15 \mathrm{mg} / \mathrm{kg}$ against P388 administered on days 1 and 5 were enhanced by CNG. Although mice treated with ADM at $15 \mathrm{mg} / \mathrm{kg}$ died earlier than non-treated controls on days 1 and 2 against L1210, P388 and EL-4, CNG with ADM was effective in prolonging the survival period.
\end{abstract}

As reported, conagenin (CNG) stimulates activated $\mathrm{T}$ cells to produce lymphokines and to generate antitumor effector cells in vitro and in vivo ${ }^{1,2)}$. It has been shown that CNG prevents the reduction in number of platelets in peripheral blood of mice given antitumor agents and improves their lethal toxicity by its modulatory activity of lymphokine production ${ }^{3,4)}$.

It is known that myelosuppression induced by antitumor agents is one of the limiting factor for cancer chemotherapy. Recently, reports have accumulated on cytokines and cytokine inducers which reduce myelosuppression induced by antitumor agents and which are chemo- and radioprotector for cancer chemotherapy ${ }^{5 \sim 12)}$. In this context, we thought that CNG could be applied as a chemoprotector and found that it improved the efficacy of antitumor agents at sublethal doses. In this paper, we report the effect of CNG on improvement of antitumor efficacy of antitumor agents in tumor bearing mice.

\section{Materials and Methods}

Mice

$\overline{\mathrm{CDF}}_{1}, \mathrm{DBA} / 2$ and $\mathrm{C} 57 \mathrm{BL} / 6$ mice (6 weeks old, female) were purchased from Chales River Japan Inc. (Kanagawa, Japan) and were maintained under specific pathogen-free conditions at $23 \pm 2{ }^{\circ} \mathrm{C}$ and $55 \pm 5 \%$ humidity. They were employed for experiments at 8 to
10 weeks of age.

\section{Conagenin and Other Chemicals}

Conagenin (CNG) was prepared by KANEKA Co. Ltd. (Osaka, Japan) according to procedures reported previously ${ }^{13}$. Cyclophosphamide (CY; Shionogi \& Co. Ltd., Osaka, Japan), adriamycin (ADM; Kyowa Hakko Kogyo Co. Ltd., Tokyo, Japan) and mitomycin C (MMC; Kyowa Hakko Kogyo Co. Ltd., Tokyo, Japan) were used as antitumor agents. For experiments, CNG and other drugs were dissolved in sterile saline.

Assessment for Antitumor Activity of Combination of $\mathrm{CNG}$ and Antitumor Agents

L1210 lymphoid leukemia cells, P388 monocytic leukemia cells and EL-4 thymoma cells were maintained in $\mathrm{CDF}_{1}, \mathrm{DBA} / 2$ and $\mathrm{C} 57 \mathrm{BL} / 6$ mice weekly intraperitoneal transplantation, respectively. These cells were inoculated iv to the tail vein of mice on day 0 with inoculum size indicated in the figure and tables. Antitumor agents were administered ip in schedules indicated in the figure and tables, and CNG at $5 \mathrm{mg} / \mathrm{kg}$ was administered ip on days 1 to 10 after the tumor inoculation. Antitumor activity was determined by monitoring the survival day of mice at 40 days. 40 -day survivors were designated as cured mice.

Statistical Analysis

The statistical significance of the data was analyzed by Mann-Whitney $U$-test. 


\section{Results}

Firstly, the effect of CNG on antitumor effect of $\mathrm{CY}$ against L1210 was investigated, since CNG reduces toxicity of $\mathrm{CY}$ in increasing the number of surviving mice given a sublethal dose of $\left.\mathrm{CY}^{4}\right) \cdot \mathrm{CDF}_{1}$ mice were inoculated iv with $1 \times 10^{3}$ L1210 cells and the effect of $\mathrm{CNG}$ on the antitumor efficacy of $\mathrm{CY}$ was examined. $\mathrm{CNG}$ at $5 \mathrm{mg} / \mathrm{kg}$, which are effective in enhancing lymphokine production by $\mathrm{T}$ cells and preventing reduction of platelets induced by antitumor agents in mice $^{1 \sim 3)}$, was administered ip to mice through experiments reported in this paper. As shown in Fig. 1, the antitumor effect of $\mathrm{CY}$ at $300 \mathrm{mg} / \mathrm{kg}$ ip on days 1 and 2 or on days 1, 5 and 9 after L1210 cells inoculation was enhanced by $\mathrm{CNG}$ in increasing the number of survival mice, although CNG alone did not exhibit any antitumor activity against $\mathrm{L} 1210$. The survival period of mice given CY alone at $300 \mathrm{mg} / \mathrm{kg}$ on days 1 and 2 was shorter than that of non-treated mice indicating drug toxicity and the number of cured mice was 3 out of 10 , whereas $\mathrm{CY}$ with $\mathrm{CNG}$ treatment prolonged the survival period and 8 out of 10 mice were tumor-free (Fig. 1a and Table 1). Although the administration of $\mathrm{CY}$ alone on days 1, 5 and 9 was less toxic than on days 1 and 2, and the number of cured mice was 4 out of 10 , all mice were cured by the treatment with CNG and CY (Fig. 1b and Table 1).

The effect of CNG with CY in DBA/2 mice inoculated with P388 cells and C57BL/6 mice inoculated with EL-4 cells was examined. CNG alone did not exhibit antitumor activity against P388 or EL-4. As shown in Table 1, CNG was effective in prolonging the survival period of mice given $\mathrm{CY}$ on days 1 and 2, and on days 1,5 and 9 against EL-4. The survival period of mice given CNG with CY against P-388 was longer than that of mice treated with
Fig. 1. Antitumor effect of cyclophosphamide(CY) combined with CNG on L1210 leukemia.

$\square$ control, o CY, $\bullet \mathrm{CY}+\mathrm{CNG}, \mathbf{C N G}$.

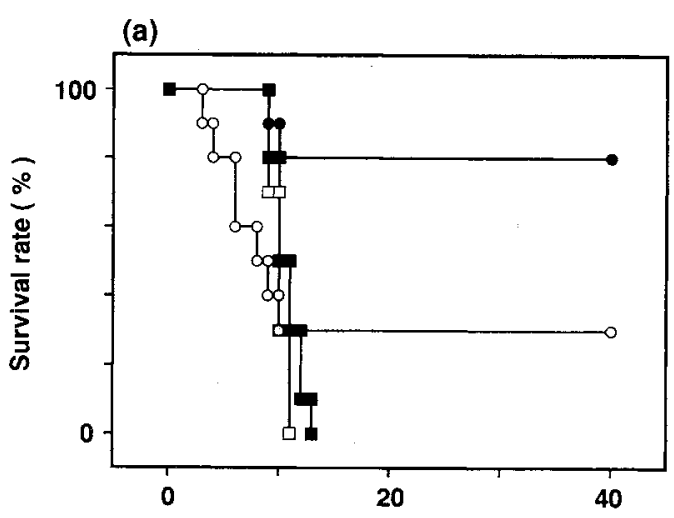

(b)

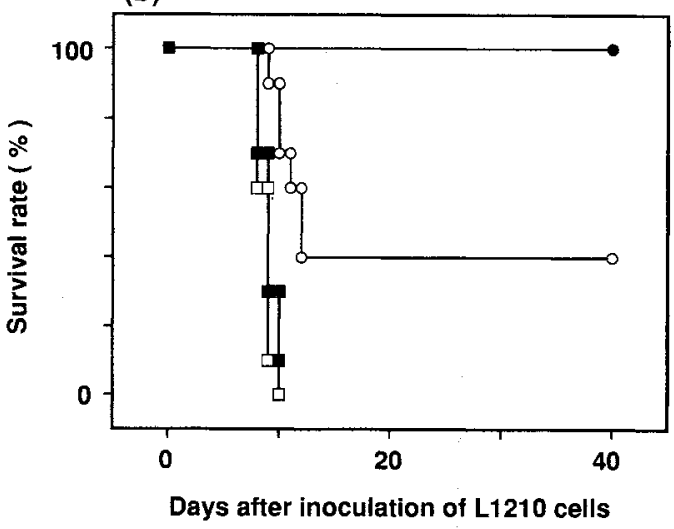

$1 \times 10^{3} \mathrm{~L} 1210$ cells were inoculated iv on day 0 to $\mathrm{CDF}_{1}$ mice. CNG $(5 \mathrm{mg} / \mathrm{kg})$ on day 1 to 10 and CY $(300 \mathrm{mg} / \mathrm{kg})$ on days 1 and 2 (a) or on days 1, 5 and 9 (b) were administered ip. Each group consisted of 10 mice.

Table 1. Antitumor effect of cyclophosphamide (CY) combined with CNG on murine leukemias.

\begin{tabular}{|c|c|c|c|c|}
\hline \multicolumn{2}{|c|}{ Therapy on days (days) } & \multicolumn{3}{|c|}{ Mean survival day ${ }^{a}$ (No. of cured mice/No. of treated mice) } \\
\hline $\begin{array}{c}\mathrm{CNG} \\
(5 \mathrm{mg} / \mathrm{kg})\end{array}$ & $\begin{array}{c}\mathrm{CY} \\
(300 \mathrm{mg} / \mathrm{kg})\end{array}$ & L1210 & P388 & EL-4 \\
\hline- & - & $10.0 \pm 0.8(0 / 10)$ & $7.2 \pm 0.4(0 / 10)$ & $12.0 \pm 0.7(0 / 10)$ \\
\hline- & 1,2 & $6.6 \pm 2.8(3 / 10)$ & $5.7 \pm 2.2(0 / 10)^{\#}$ & 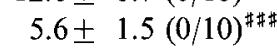 \\
\hline $1 \sim 10$ & 1,2 & 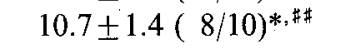 & $8.8 \pm 2.0(0 / 10)^{* *}$ & $9.3 \pm 3.6(2 / 10)^{* *}$ \\
\hline- & - & $8.7 \pm 0.7(0 / 10)$ & $7.0 \pm 0.7(0 / 10)$ & $11.3 \pm 1.3(0 / 10)$ \\
\hline- & $1,5,9$ & $10.7 \pm 1.2(4 / 10)^{\# \# \# ~}$ & $8.2 \pm 3.0(0 / 10)$ & $14.6 \pm 10.3(5 / 10)$ \\
\hline $1 \sim 10$ & $1,5,9$ & $>40.0 \quad(10 / 10)^{*}$ & $9.8 \pm 2.2(0 / 10)$ & $25.0 \pm 5.3(7 / 10)^{\# \# \#}$ \\
\hline
\end{tabular}

$1 \times 10^{3} \mathrm{~L} 1210$ cells to $\mathrm{CDF}_{1}$ mice, $1 \times 10^{5} \mathrm{P} 388$ cells to $\mathrm{DBA} / 2$ mice and $1 \times 10^{5} \mathrm{EL}-4$ cells to $\mathrm{C} 57 \mathrm{BL} / 6 \mathrm{mice}$ were inoculated iv on day 0 . CNG and CY were administered ip in schedules indicated. Each group consisted of 10 mice. ${ }^{a}$ Mean survival day \pm standard deviation excluded 40 -day survivors. ${ }^{*} P<0.05$ and ${ }^{*} P<0.01$ in comparison with $C Y$ alone.

${ }^{\sharp} P<0.05,{ }^{\# \#} P<0.01$ and ${ }^{\# \#} P<0.001$ in comparison with non-treated control. 
Table 2. Antitumor effect of mitomycin C (MMC) combined with $\mathrm{CNG}$ on murine leukemias.

\begin{tabular}{|c|c|c|c|c|}
\hline \multicolumn{2}{|c|}{ Therapy on days (days) } & \multicolumn{3}{|c|}{ Mean survival day (No. of cured mice/No. of treated mice) } \\
\hline $\begin{array}{c}\mathrm{CNG} \\
(5 \mathrm{mg} / \mathrm{kg})\end{array}$ & $\begin{array}{c}\mathrm{MMC} \\
(10 \mathrm{mg} / \mathrm{kg})\end{array}$ & L1210 & P388 & EL-4 \\
\hline - & - & $10.0 \pm 0.8(0 / 10)$ & $7.2 \pm 0.4(0 / 10)$ & $12.0 \pm 0.7(0 / 10)$ \\
\hline- & 1,2 & 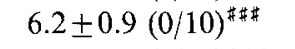 & $6.8 \pm 3.5(0 / 10)$ & $8.6 \pm 1.7(0 / 10)^{\# \#}$ \\
\hline $1 \sim 10$ & 1,2 & $8.6 \pm 1.2(0 / 10)^{* * *}$ & $7.7 \pm 2.9(0 / 10)$ & $11.3 \pm 2.1(0 / 10)^{* *}$ \\
\hline- & - & $8.7 \pm 0.7(0 / 10)$ & $7.0 \pm 0.7(0 / 10)$ & $11.3 \pm 1.3(0 / 10)$ \\
\hline - & 1,5 & $11.2 \pm 3.2(0 / 10)$ & $12.7 \pm 5.2(0 / 10)^{\#}$ & $12.5 \pm 0.7(0 / 10)^{\#}$ \\
\hline $1 \sim 10$ & 1,5 & 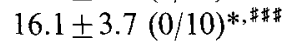 & $13.1 \pm 4.2(0 / 10)^{\# \# \#}$ & $12.7 \pm 1.4(0 / 10)^{\#}$ \\
\hline
\end{tabular}

$1 \times 10^{3} \mathrm{~L} 1210$ cells to $\mathrm{CDF}_{1}$ mice, $1 \times 10^{5} \mathrm{P} 388$ cells to $\mathrm{DBA} / 2$ mice and $1 \times 10^{5} \mathrm{EL}-4$ cells to $\mathrm{C} 57 \mathrm{BL} / 6$ mice were inoculated iv on day 0 . CNG and MMC were administered ip in schedules indicated. Each group consisted of 10 mice. ${ }^{*} P<0.05,{ }^{*} P<0.01$ and ${ }^{* * *} P<0.001$ in comparison with MMC alone. ${ }^{\sharp} P<0.05,{ }^{\sharp} P<0.01$ and ${ }^{\# \#} P<0.001$ in comparison with non-treated control.

Table 3. Antitumor effect of adriamycin (ADM) combined with CNG on murine leukemias.

\begin{tabular}{|c|c|c|c|c|}
\hline \multicolumn{2}{|c|}{ Therapy on days (days) } & \multicolumn{3}{|c|}{ Mean survival day ${ }^{a}$ (No. of cured mice/No. of treated mice) } \\
\hline $\begin{array}{c}\mathrm{CNG} \\
(5 \mathrm{mg} / \mathrm{kg})\end{array}$ & $\begin{array}{c}\mathrm{ADM} \\
(15 \mathrm{mg} / \mathrm{kg})\end{array}$ & L1210 & P388 & EL-4 \\
\hline - & - & $10.0 \pm 0.8(0 / 10)$ & $7.2 \pm 0.4(0 / 10)$ & $12.0 \pm 0.7(0 / 10)$ \\
\hline - & 1,2 & $6.8 \pm 1.3(0 / 10)^{\ddagger}$ & $6.6 \pm 1.8(0 / 10)$ & $11.0 \pm 6.6(0 / 10)$ \\
\hline $1 \sim 10$ & 1,2 & $14.2 \pm 5.8(0 / 10)^{*}$ & $11.3 \pm 4.5(0 / 10)^{* *, \#}$ & $15.9 \pm 7.9(2 / 10)^{*}$ \\
\hline- & - & $8.7 \pm 0.7(0 / 10)$ & $7.0 \pm 0.7(0 / 10)$ & $11.3 \pm 1.3(0 / 10)$ \\
\hline- & 1,5 & 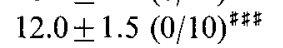 & $11.5 \pm 1.7(0 / 10)^{\# \# \#}$ & $17.4 \pm 0.7(0 / 10)$ \\
\hline $1 \sim 10$ & 1,5 & $12.5 \pm 1.1(0 / 10)^{\# \# \#}$ & $13.8 \pm 2.6(0 / 10)^{* \text {,\#\# }}$ & $20.2 \pm 7.0(0 / 10)^{\#}$ \\
\hline
\end{tabular}

$1 \times 10^{3} \mathrm{~L} 1210$ cells to $\mathrm{CDF}_{1}$ mice, $1 \times 10^{5} \mathrm{P} 388$ cells to DBA/2 mice and $1 \times 10^{5} \mathrm{EL}-4$ cells to C57BL/6 mice were inoculated iv on day $0 . \mathrm{CNG}$ and ADM were administered ip in schedules indicated. Each group consisted of 10 mice. ${ }^{a}$ Mean survival day \pm standard deviation excluded 40 -day survivors. ${ }^{*} P<0.05$ and ${ }^{*} P<0.01$ in comparison with ADM alone.

${ }^{\sharp} P<0.05,{ }^{\# \#} P<0.01$ and ${ }^{\# \# \#} P<0.001$ in comparison with non-treated control.

CY alone on both schedules of CY treatment, but the improvement of antitumor activity of CY by CNG was not observed.

The effect of CNG on antitumor efficacy of MMC and ADM was also confirmed. CNG augmented the antitumor effect of MMC at $10 \mathrm{mg} / \mathrm{kg}$ on days 1 and 5 against L1210 significantly (Table 2). On the other hand, L1210, P388 or EL-4 bearing mice given ADM at $15 \mathrm{mg} / \mathrm{kg}$ on days 1 and 2 died earlier than non-treated control (Table 3). However, treatment with CNG and ADM prolonged the survival period of mice significantly. CNG augmented the antitumor effect of ADM on days 1 and 5 against $\mathrm{P} 388$ significantly.

\section{Discussion}

It has been believed that improvement of dose intensity of antitumor agent is an important strategy in cancer chemotherapy. Recently, low molecular immunomodulators AS 101 and swainsonine, have been shown to be chemo- and radioprotective in cancer chemotherapy, protecting against myelosuppression induced by chemo- therapy and reducing lethal toxicity of antitumor agents $^{5 \sim 8)}$.

As reported in previous papers, CNG stimulates activated $T$ cells to enhance production of some lymphokines such as IL-2, IL-3, IL-4 and GM-CSF, and suppresses monokine production by macrophages in tumor bearing mice ${ }^{1,2)}$. Furthermore, it decreases platelet reduction in peripheral blood of mice given antitumor agents suggesting a modulatory effect on cytokine production by $\mathrm{T}$ cells in bone marrow cells and reduces the lethal toxicity of antitumor agents such as $\mathrm{CY}, \mathrm{MMC}$, and irradiation by $\mathrm{X}$ ray $^{3,4)}$. Thus, we thought that CNG could be applied for adjuvant chemotherapy in cancer treatment and the effect of CNG with other antitumor agents at sublethal dose was examined against murine leukemia as a tumor model.

CNG was obviously effective in improving antitumor activity of CY at $300 \mathrm{mg} / \mathrm{kg}$ in either treatment on days 1 and 2, and on days 1, 5 and 9 against L1210 and EL-4, although CY with or without CNG was not effective on P388 bearing mice (Table 1). CNG enhanced the antitumor activity of CY in prolonging survival in L1210 and EL-4 bearing mice and in increasing the number of cured mice (40-day survivors). The effect of CNG might be due to reduction of toxicity of $\mathrm{CY}$ in the treatment 
with $\mathrm{CY}$ on days 1 and 2, because the survival period of mice treated with $\mathrm{CY}$ alone was shorter than that of non-treated controls. The effect of CNG was confirmed with MMC and ADM in treatment on days 1 and 2, and on days 1 and 5 against L1210, P388 and EL-4. In mice treated with $\mathrm{MMC}$ and $\mathrm{ADM}$ on days 1 and $5, \mathrm{CNG}$ enhanced the antitumor effect of MMC against L1210, and ADM against P388, but could not increase the number of cured mice (Tables 2 and 3). CNG could reduce the toxicity of ADM on days 1 and 2, and consequently prolong the survival period of L1210, P388 and EL-4 bearing mice (Table 3). Now, the effect of CNG in combination with antitumor substances is testing on murine solid tumor model.

It can be concluded that $\mathrm{CNG}$ augments the antitumor efficacy of $\mathrm{CY}$ and other antitumor agents such as MMC and ADM at sublethal doses against murine leukemias and could be effective in improving dose intensity. It has been currently comfirmed that $\mathrm{CNG}$ augments to produce megakaryocytes in human bone marrow cell cultures. CNG may be valuable for clinical trials in reduction of toxicity in cancer chemotherapy.

\section{Acknowledgments}

This work was supported in part by a Grant-in-Aid for Cancer Research from the Ministry of Education, Science and Culture, Japan.

\section{References}

1) Kawatsu, M.; T. Yamashita, M. Osono, M. Ishizuka \& $\mathrm{T}$. TAKEUCHI: $\mathrm{T}$ cell activation by conagenin in mice. J. Antibiotics 46: 1687 1691, 1993

2) Kawatsu, M.; T. Yamashita, M. Osono, T. Masuda, M. IsHIZUKA \& T. TAKEUCHI: Effect of conagenin in tumor bearing mice antitumor activity, generation of effector cells and cytokine production. J. Antibiotics 46: $1692 \sim 1698,1993$

3) Kawatsu, M.; T. Yamashita, M. Ishizuka \& T. TAKEUCHI: Effect of conagenin on thrombocytopenia induced by antitumor agents in mice. J. Antibiotics 47: $1123 \sim 1129,1994$

4) Ishizuka, M.; T. Yamashita, M. Kawatsu, T. Takeuchi, T. Katsumi \& T. Shiraishi: Effect of conagenin, a low-molecular-weight immunomodulator on platelet production. In Recent Advances in Chemotherapy. Proceedings of the 18th congress of chemotherapy. Ed., J. EINHORN et al., pp. 772 773, American Society for Microbiology, Washington, 1994

5) Oredipe, O. A.; S. L. White, K. GrzegorzewsKi, B. L. Gause, J. K. Cha, V. A. Miles \& K. Olden: Protective effects of swainsonine on murine survival and bone marrow proliferation during cytotoxic chemotherapy. $\mathbf{J}$. Natl. Cancer Inst. 83: 1149 1156, 1991

6) Kalechman, Y.; M. Albeck, M. Oron, D. Sobelman, M. Gurwith, S. N. Seghal \& B. SRedn: Radioprotective effects of the immunomodulator AS101. J. Immunol. 145: $1512 \sim 1517,1990$

7) Kalechman, Y.; M. Albeck, M. Oron, D. Sobelman, G, Horwith, T. Kirsch, B. Maida, S. N. Sehgal \& B. SREDNI: Protevtive and restorative role AS101 in combination with chemotherapy. Cancer Res. 51: $1499 \sim 1503$, 1991

8) Kalechman, Y; A. Shani, I. Sotnik-Barkai, M. Albeck \& B. SREDNI: The protective role of ammonium trichloro (dioxoethylene- $O, O^{\prime}$ ) tellurate in combination with several cytotoxic drugs acting by different mechanisms of action. Cancer Res. 53: 5962 5969, 1993

9) Miyazaki, H.; Y. Yoshikai, M. Tanaka, Y. Takeda, S. TAKEO \& K. NOMOTO: Protective effect of SPR-901 (RBS) on the decrease of peripheral leukocyte number in 5-fluorouraciltreated mice. Int. J. Immunopharmac. 14: $11 \sim 17,1992$

10) Castelli, M. P.; P. L. Black, M. Schneider, R. Pennington, F. Abe \& J. E. TAlmadge: Protective, restorative, and therapeutic properties of recombinant human IL-1 in rodent models. J. Immunol. 140: $3830 \sim 3837,1988$

11) Tanikawa, S.; M. Nose, Y. Aoki, K. Tsuneoka, M. SHIKITA \& N. NARA: Effects of recombinant human granulocyte colony-stimulating factor on the hematologic recovery and survival of irradiated mice. Blood 76: $445 \sim 449,1990$

12) Neta, R.; R. Perlstein, S. N. Vogel, G. D. Ledney \& J. ABRAMS: Role of interleukin 6 (IL-6) in protection from lethal irradiation and in endocrine responses to IL-1 and tumor necrosis factor. J. Exp. Med. 175:689 694, 1992

13) Yamashita, T.; M. Iijima, H. Nakamura, K. Isshiki, H. Naganawa, S. Hattori, M. Hamada, M. IshrzuKa \& T. TAKEUCHI: Conagenin, a low molecular weight immunomodulator produced by Streptomyces roseosporus. J. Antibiotics 44: 557 559, 1991 